\title{
How does the position of firms in the supply chain affect their performance? An empirical study
}

\author{
Siddharth Arora ${ }^{1}$ and Alexandra Brintrup ${ }^{2^{*}}$ (I)
}

\author{
*Correspondence: \\ Ab702@cam.ac.uk \\ ${ }^{2}$ Department of Engineering, \\ Institute for Manufacturing, \\ University of Cambridge, \\ Cambridge CB3 OFS, UK \\ Full list of author information \\ is available at the end of the \\ article
}

\begin{abstract}
The relationship between a firm and its supply chain has been well studied, however, the association between the position of firms in complex supply chain networks and their performance has not been adequately investigated. This is primarily due to insufficient availability of empirical data on large-scale networks. To addresses this gap in the literature, we investigate the relationship between embeddedness patterns of individual firms in a supply network and their performance using empirical data from the automotive industry. In this study, we devise three measures that characterize the embeddedness of individual firms in a supply network. These are namely: centrality, tier position, and triads. Our findings caution us that centrality impacts individual performance through a diminishing returns relationship. The second measure, tier position, allows us to investigate the concept of tiers in supply networks because we find that as networks emerge, the boundaries between tiers become unclear. Performance of suppliers degrade as they move away from the focal firm (i.e., Toyota). The final measure, triads, investigates the effect of buying and selling to firms that supply the same customer, portraying the level of competition and cooperation in a supplier's network. We find that increased coopetition (i.e., cooperative competition) is a performance enhancer, however, excessive complexity resulting from being involved in both upstream and downstream coopetition results in diminishing performance. These original insights help understand the drivers of firm performance from a network perspective and provide a basis for further research.
\end{abstract}

Keywords: Complex supply networks, Supply network performance, Centrality, Triads

\section{Introduction}

Starting as early as 1966, the study of how a focal firm is affected by its supply chain gathered scholarly attention (Evan 1966). Resource dependency theory (Pfeffer and Salancik 1978), and institutional theory (Di Maggio and Powell 1983), framed how organizations could influence each other and affect each others' performance.

While these theories mostly focused on the dyadic relationship between two firms, starting in the 1980s scholars developed perspectives on the new networked supply chains distinguishing it from pure hierarchies with permanent ties between a firm and its links, and a pure market with sporadic, transactional relationships (e.g. Podolny 1993). author(s) and the source, provide a link to the Creative Commons licence, and indicate if changes were made. The images or other third party material in this article are included in the article's Creative Commons licence, unless indicated otherwise in a credit line to the material. If material is not included in the article's Creative Commons licence and your intended use is not permitted by statutory regulation or exceeds the permitted use, you will need to obtain permission directly from the copyright holder. To view a copy of this licence, visit http:// creativecommons.org/licenses/by/4.0/. 
The term supply chain may be misleading as it can brush over non-hierarchical relationships such as cooperation and competition. Further, suppliers often belong to multiple supply chains. Supply networks are characterized by a network of firms with stronger ties sustained over longer durations, enforced by repeated exchanges, and lack a controlling authority that resolves disputes or imposes rule. Benefits of supply networks include the building of trust, flexibility, efficiency and cooperative knowledge exchange (Podolny 1993), higher innovation rates (Powell et al. 2005), lower costs (Uzzi and Gillespie 2002), and better performance. Researchers also cautioned that too much dependence on the network may bring diminishing returns to firms due to loss of independence, social obligations prevailing over economic ones, and barriers of access to the larger market (Powell 1990; Uzzi 1997).

Empirical evidence showed that supply networks consist not only of hierarchical links, but also lateral links, triadic formations, and reverse loops (Uzzi 1997; Borgatti and Li 2009a, b; Lomi and Pattison 2006; Kim et al. 2011) and posited that this complex structure should affect system-wide properties such as robustness, and firm-level performance.

The application of network theory to supply networks is still in its early days. Although past studies investigated the structural properties of the networks (Saito et al. 2007; Ohnishi et al. 2009, 2010; Fujiwara and Aoyama 2010; Bernard et al. 2014; Mizuno et al. 2014; Inoue and Todo 2019), the relationship between the position of embedded firms and their performance have been less investigated. Bernard et al. (2014) investigate the effects of supplier networks and supplier location on firm performance, using detailed buyer-supplier data for a Japanese production network. Cingolani et al. (2017) proposed a three-faceted measure of network centrality that captures distinct roles of a country at upstream, midstream and downstream stages of the international production process. Seiler et al. (2020) provided evidence that profitability is related to connectedness and market share. Using measures of centrality for jurisdiction and affiliates, Nakamoto et al. (2019) identified intermediate firms that are at high risk in international profit shifting. It is worth noting that studies have investigated how the supply-network affect firm performance in the context of natural disasters (Todo et al. 2013; Barrot and Sauvagnat 2016; Kashiwagi et al. 2018).

To statistically examine structural effects, one would need to collect data on supply networks that encompasses a large number of interdependent firms. While most studies focus on a few suppliers around the focal firms, we have prepared a dataset that comprehensively maps the very large supply chain network of Toyota. The limited number of large-scale empirical studies consisted of Uzzi (1997), who discussed how the extent of embeddedness was related to the survival rates of firms in the New York Garment Industry; Lomi and Pattison (2006), who examined the Fiat Panda network and showed the various non-hierarchical "motifs", or patterns of linkages, such as triadic relationships. Brintrup (2011) mapped for the first time a large scale supply network consisting of more than 3000 firms characterising the Toyota supply chain, and showed how the resilience of Toyota's network was determined by complex topological interdependencies among firms, and that failures in the network can cause cascades of disruptions. Kim et al. (2011) examined the Honda-Acura network, displaying how complex network analysis techniques could be applied to identify 
important actors. Using dataset for a manufacturing joint venture network, Carnovale and Yeniyurt (2015) emphasise that innovation in a supply chain depends on the network structure of interfirm relationships.

In addition to the scarcity of large scale empirical studies, literature lacks design of appropriate position measures that capture the function and organisation of a supply network. Extant studies have mostly focussed on the application of existing metrics which do not fully accommodate intricacies of supply chains.

In this paper, we address these gaps by analysing a large-scale map of the Toyota supply network and investigate how positions of individual firms in the network impact their performance. Specifically, this study aims to provide insights into the following three major questions: (1) Does the position a firm occupies in the network consistently impact its performance? (2) Does the position of the supply firm consistently impact its performance (3) And consequently, are there specific upstream or downstream linkage patterns that lend themselves to better performance for the focal firm?

Studying Toyota also allows us to utilise discussions describing its specific supply chain management strategy.

In this study, we make the following three contributions to the study of complex supply networks. First, we devise three measures that characterise the supply network position for individual firms. Our goal is to find metrics that are simple yet effective in characterising supply network embeddedness and use them to measure how firm position impacts performance. These are namely: (a) centrality, (b) tier position, and, (c) triads. Centrality quantifies the dependency on a given firm as a result of its position, helping us to go beyond local connections. We find that the larger network does indeed impact individual performance through a diminishing returns relationship. The second measure, tier position, investigate the average tier level that a firm positions itself. We find that, within the industrial boundary of analysis, the performance of suppliers degrades as they move away from the focal firm (i.e., Toyota in this case). The final measure, triads, investigates the effect of participating in inter-tier relationships and portrays the level of competition and cooperation in a supplier's network. We find that increased coopetition to be a performance enhancer, however excessive complexity resulting from being involved in both upstream and downstream coopetition degrades performance.

The paper is arranged as follows. In "Data and hypothesis" section, we present the literature review and data for Toyota's supply chain network and state the hypotheses tested in this study. In "Methods" section, we present the methodology, while "Results" section presents the results. Discussion, limitations, and directions for future work are provided in "Discussion" section. Finally, we present the conclusions and managerial implications of this study are discussed in "Conclusions and managerial implications" section.

\section{Data and hypothesis}

In this section, we first present the relevant literature review ("Literature review: the Toyota supply chain" section) and data for the Toyota supply chain ("Data" section), followed by hypothesis and theory development to quantify the complexity of the supply chain network ("Theory and hypothesis development" section). 


\section{Literature review: the Toyota supply chain}

Toyota's lean manufacturing policy is supported by its complex yet robust supply network (Nishiguchi 1994). A number of distinctive characteristics have been hypothesized about the Toyota supply chain model. The first is its tiered supply chain, in which Toyota has intensive relationships with a relatively small number of first-tier suppliers who take responsibility to provide modules of parts rather than independent components, meaning that first-tier firms take on a greater degree of technological responsibility for product development.

The supply networks have both material-flow links, and shared-ownership linksleading to what is known as a "Keiretsu" structure, presumed to enable long-term, trustoriented relationships which allow co-location, investment in dedicated manufacturing assets, and 'target costing' mechanisms (Sambharya and Banerji 2006). These ties are augmented by other groupings, notably supplier associations, which facilitate the flow of technical expertise with Toyota engineers assisting the technical development of the supplier base (Dyer and Nobeoka 2000). These relationships facilitate operational and technological integration, resulting in low variance and risk, and therefore low cost and high efficiency (Dyer and Nobeoka 2000; Wilhelm and Kohlbacher 2011). Okamuro (2001) reported that the firms supplying to all major Japanese automakers are safeguarded from demand fluctuations and that the variance in suppliers' earnings is consistently lower compared to that of the manufacturers, thus allowing suppliers to plan and invest in the longer term. Finally, there is a relatively high degree of upstream and downstream dependency between buyers and suppliers enforcing cooperative ties even when there is competition among suppliers (Nishiguchi and Beaudet 1998).

Although many discussions on Toyota's supply chain exist the discussion currently suffers from a few gaps: first is a lack of available studies that describe the larger network on which Toyota relies and the performance of suppliers within. Secondly, discussions are now rather old: Lincoln and Shimotani (2009) discuss the fading away of Japanese keiretsu structures, and their replacement by overseas alternatives except for a few close suppliers, as the competitive advantage that keiretsu-style supply management offered began to diminish in the'90s. Standardisation, modular products, and automated collaboration software reduced the need for tight control and coordination, which could have allowed overseas cheaper alternatives to play a bigger role in production (Sturgeon 2002). Therefore, a study of firm-level performance effects of today's macro supply network structure is beneficial. Toyota's network is uniquely placed to offer insight into performance implications of embeddedness, due to availability of related literature, and its large and complex scale, allowing us to carry out network theoretic analysis.

\section{Data}

We study the Japanese automotive industry due to the following reasons. First, the Japanese automotive industry has been stable during the data collection period. Second, the automotive supply chain in Japan is of sufficiently large scale to allow us to examine network effects. Third, suppliers in Japan engage in long term relationships repetitively working together over extended periods, giving us more confidence to engage in a crosssectional study. 
Within the Japanese automotive industry, we focus on the network of Toyota Motor Company. Focusing on the automotive industry allows us to extract data from a single, comprehensive database (Marklines Automotive Information Platform ${ }^{1}$ ). The database allows us to draw a network map of who-supplies-to-whom. It should be noted that data is cumulative: once a supplier marks itself as a supplier to a client, this data continues residing in the dataset, unless either the buyer or the supplier firm removes this relationship explicitly from the database. Data is cross-sectional and agglomerative, although most data has been uploaded post-2007. In addition to the network map, we used a secondary data source (OneSource ${ }^{2}$ ) to query financial information and cross-validate data gathered from the first database. The database is licensed, and their access is restricted.

Data has been extracted in 2015. We first identified the direct suppliers of Toyota. We then conducted individual searches on each direct supplier, to identify suppliers of suppliers, and their other clients. This recursive process continued until no other supply tier was found. The resulting network has 2120 nodes and 4756 links. It should also be highlighted that the suppliers in the dataset define themselves, at least partially, as automotive product manufacturers, although an automotive supply chain would also include raw material providers and electronic components. Hence, the dataset is not exhaustive and our findings regarding the impact of firm position apply to firms serving with the same industry. Further details regarding the firm-level data and validation are presented in "Results" section.

\section{Theory and hypothesis development}

\section{Positioning for optimal business flow: centrality in supply networks}

Researchers have distinguished between supplier and buyer connections and suggested that the number of supplier links (in-degree centrality) is proportional to a firm's operational load (Kim et al. 2011), and are critical in architectural or technical product change management. The number of buyers a firm has (out-degree centrality) is proportional to its load in demand and resource integration (Kim et al. 2011).

While direct links of firms are important, they do not encapsulate the complexity of the entire network. A supply network has an underlying material flow logic, as it facilitates the assembly of the final product. So, a firm does not only depend on its direct links but to its entire extended network. If a supplier's supplier runs into production or delivery challenges, the subsequent products might be impacted, even if they do not directly depend on that supplier.

Similarly, a buyer that is facing issues may affect its supplier who is dependent on the buyer's business. In addition, the affected supplier's other connections may suffer from this disruption.

Quantifying the extent of such dependencies is nontrivial. We examine three measures: closeness centrality, betweenness centrality, and eigenvector centrality. We chose these measures due to their relevance and low computational cost.

Closeness centrality measures the distance of a given node from all the other nodes in a network. This measure is often used to identify nodes that are instrumental in

\footnotetext{
${ }^{1}$ www.marklines.com (Last assessed: Jan 2020).

2 www.onesource.com (Last assessed: Jan 2020).
} 
disseminating information. Kim et al. (2011) suggest that it could highlight a supplier's autonomy in a network: the closer a firm is to other firms, the more information visibility it has, which could translate into operational benefits. However firms in a supply chain typically work towards bringing products downstream, and the direction of links to the assembler should be the one that matters. Hence, taken in the context of business and operational flow, this metric does not readily give a sense of operational dependencies as it essentially captures information flow regardless of the inherent directionality in a supply network.

Betweenness centrality examines the number of times a node (i.e. a firm) sits on the shortest paths that link any two nodes on the network. Kim and Choi note this metric's relevance to supply chains as: "Firms with high betweenness act as a hub or pivot that transmits materials along the supply chains, and betweenness centrality relates to the extent to which a firm potentially affects the downstream firms' daily operations (e.g., lead time) and eventually the performance (e.g., final product quality) of the whole network." Although intuitive, its application to supply chains may need some tailoring. In the context of material flow in supply chains, short paths are not necessarily favourable to other paths, since the goal is simply to use all paths necessary to produce the final product.

Eigenvector centrality is defined as the principal eigenvector of the adjacency matrix computed from a given network. In the context of supply networks, the eigenvector concept would translate such that a firm that is only connected to one firm could still be influential if its connections themselves have many connections. An outsourcing strategy to a few suppliers would result in its low degree centrality, but connection to suppliers who themselves are highly connected means that the focal firm's performance may be influenced by its indirect connections. Similarly, a small third-tier supplier that has exclusive relations with a highly connected supplier such as Aisin, means that the third tier supplier becomes an important player in the network. Yan et al. (2015) proposed the nexus supplier metric based on eigenvector centrality to identify critical suppliers. However, eigenvector centrality does not capture the dynamics of business and operational flow in a supply network because it considers all links that are connected to firms regardless of their direction. Further, the underlying production logic is not accommodated.

None of these measures accommodates the intricacies of supply networks. Betweenness centrality uses shortest paths between nodes, where none exist in a supply chain, whereas closeness and eigenvector centrality capture all linkages regardless of the direction of material flow. One way to capture operational influence in supply networks could be to investigate how much business (i.e., the flow of transaction) passes through a given firm via its direct and indirect connections. This measure would indicate how many times a firm lays on paths linking other firms to the focal firm. Firms with higher numbers of such paths are those that lay on strategic positions that include them in a majority of the trade with the assembler, making its suppliers dependent on their trade, and customers dependent on their operational performance. We could not measure the flow of transactions, because we did not have access to the transactions value data. Thus, we use the path counts as a proxy for transactions. Counting paths is better than counting dyadic links because paths not only capture how dependent a firm's suppliers and clients are to the firm but also capture how dependent are a firm's suppliers' suppliers 
to the focal firm, going all the way to the bottom of the chain. We refer to this metric as "Supply Network Centrality (SNC)", a formal description of which is given in "Regression variables" section.

Once SNC is captured, one could extend its implication on performance by going back to the arguments posed by relationship theory. High SNC means high operational flow, increasing a firm's reputation and leading to better performance, but after a certain threshold diminishing returns effects might occur, as managerial attention may become overloaded and operational difficulties and inefficiencies may arise, resulting in declined performance. Therefore, we would expect that SNC has an inverted U-shape relationship with performance.

Hypothesis 1 The effect of the number of paths that pass through a firm in a supply network is characterized by diminishing returns such that the relationship is inverted U-shaped.

\section{Positioning for optimal information flow: what are tiers in a network?}

Studies show that a supply firm's access to information impacts a variety of performancerelated operational decisions, perhaps with the most studied one being demand, which helps firms make more optimal production decisions. For example, the well-known bullwhip phenomenon is observed when the variance of demand becomes increasingly amplified and distorted at each stage throughout the supply chain, resulting in unnecessary inventory and waste (Lee et al. 1997). Van Ackere et al. (1993) showed that the extent of variance amplification is directly related to the length of the chain.

Also, operational improvement activities and know-how sharing might decrease among firms as they further move away from the focal firm. For instance, Toyota's key supplier association, the Kyohokai, focuses on technical and process-based know-how exchange. We found that all Kyohokai members from our sample were Tier 1 suppliers (although 39\% of them supplied also to one another; making them Tier 2 suppliers as well). Considering the boundary of our analysis, it can be said a firm's position in the same industrial domain may relate to the accuracy and extent of information it receives, and firm performance may be adversely affected as its length of the path to the focal firm increases.

However, in networks that consist of non-hierarchical relationships, counting tiers is not obvious. Consider the clean energy product sub-network embedded within our larger network (Fig. 1). Many suppliers supply not only to Toyota but also to each other. Firms exist in different tiers.

To provide an appropriate metric for potential information distortion effects, we should re-examine the tier concept. In Fig. 1, the firm with the most links is Toyota. We observe that KRK is a Tier 1 supplier to Toyota as well as a Tier 2, because it supplies to Bosch Automotive, another Tier 1 supplier of Toyota. American Axle is Tier 2, but Tier 3 at the same time, as it supplies to a Tier 2 supplier of Toyota. In the absence of transactional information on the links, one may assign multiple tier memberships, average tier membership or take the frequencies of pathways in which a firm participates into account. For instance, products reach to Toyota from Toyoda Gosei via (Denso), (KRK, 


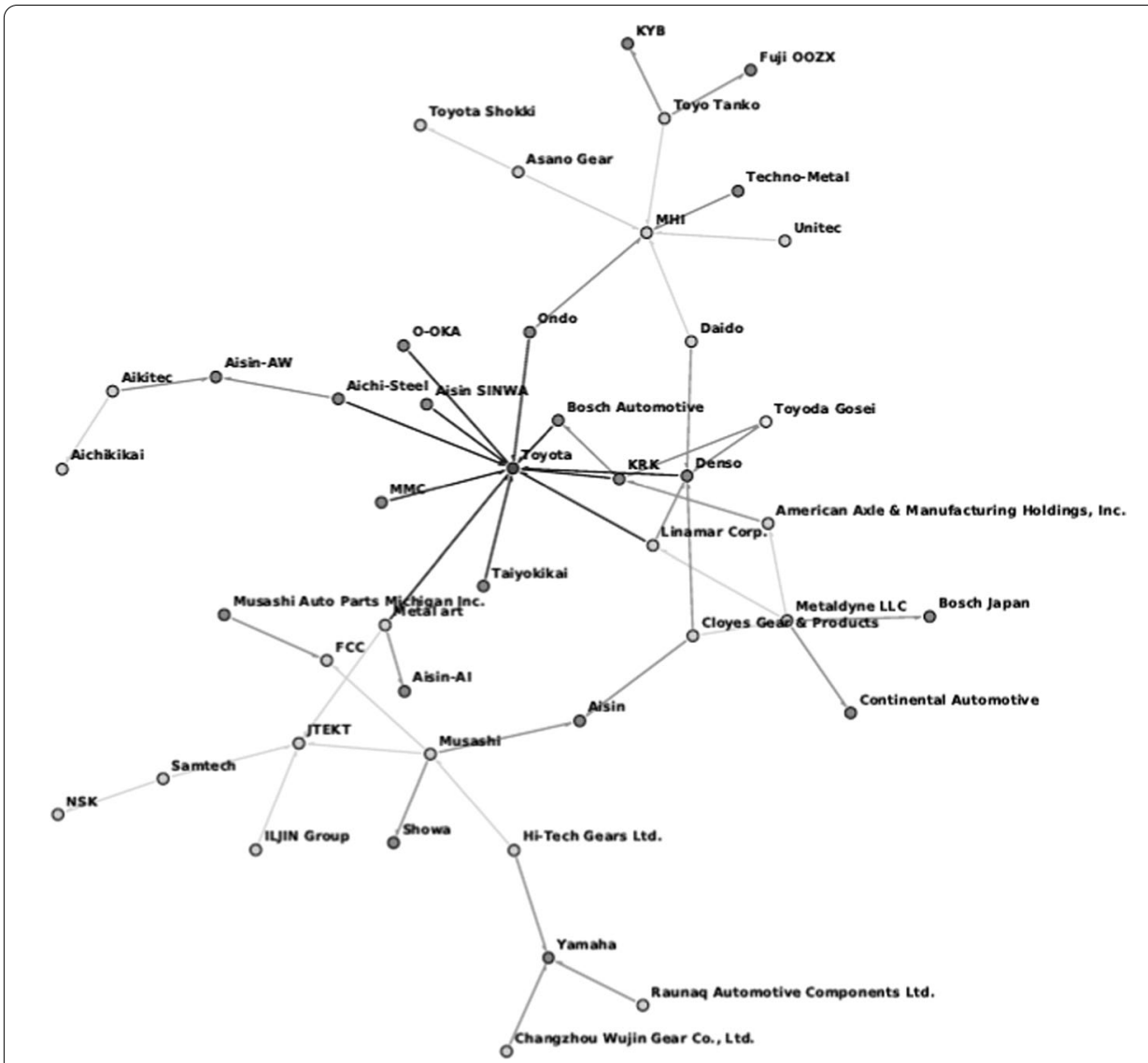

Fig. 1 Clean energy product sub-network. Several alternative path lengths exist to the focal firm

Bosch), or (KRK). There is a pathway of length 3, and two pathways of 2. If one was to model the risk of information distortion one could assign Toyoda Gosei to Tier 3 to take a conservative approach or average across path lengths.

It might be that another tier membership is appropriate for Toyoda Gosei, for instance, if most of its production is channelled to Toyota through the pathway of length 3 , but in the absence of other information, network structure provides us with a conservative measure (Brintrup et al. 2011). We refer to this metric as the "Supply Network Tier Level (SNTL)", and following previous studies, propose that it has an inverse relationship to performance for firms in a supply network.

Hypothesis 2 Within the same industry, a firm's supply network tier level and its performance have an inverse relationship.

\section{Positioning for social capital: triadic patterns}

We have discussed ways in which we can measure the impact of firm position concerning the amount of business that passes through it, and its access to information. Researchers posited that firm performance is also impacted by social relationships (Granovetter 1985). 
Relationship theory suggests that sellers and buyers perform better by focusing on a few strong, long-lasting relationships instead of dividing their attention across multiple weak relationships (Morgan and Hunt 1994). When a firm is simultaneously engaged in multiple relationships at any given point of time, its managerial attention can become overloaded (Rothaermel 2001). Firms that limit the numbers of their relationships and develop long-term ties obtain stability (Lawson et al. 2008), resulting in increased operational and financial performance.

Another strand of argument relates to risk aversion, which may cause firms to increase the number of links they have. Many manufacturers actively seek multiple suppliers for the same products to maintain competitiveness and reduce risk. Companies are even known to finance suppliers to increase the number of their suppliers. Motivations for risk aversion also apply to suppliers as they may want to reduce their dependence on a customer (Wagner and Bode 2006).

Structural embeddedness theory considers another viewpoint (Granovetter 1985). Embeddedness indicates the state of dependence of a company on both its suppliers and clients (Echols and Tsai 2005). Embeddedness has been investigated using a range of measures including degree centrality, and how tightly or loosely coupled its relationships are (Uzzi 1997). High embeddedness can serve as a proxy for the firm's reputation and status, helping it to obtain new business faster (Uzzi 1997). However, Uzzi (1997) highlighted that personal relationships between procurement officers and suppliers are likely to emerge among firms that over-connect, hindering their shift to more beneficial transactional relations.

Structural holes theory refers to a focal node as the "ego", and relationships between the ego's connections node's connections as alters. Burt (1992) found that if an ego's alters are connected, the information that one alter possesses might also be possessed by the other alter, which suggests that having a tie to both alters could be redundant. Thus, a network comprising fewer ties between alters is likely to deliver the ego with more information, which leads to better performance.

Borgatti and Li (2009a, b) noted that an application of this to supply chains is where a client's suppliers coordinate in price offerings, reducing the client's bargaining power. However, they also warned against borrowing such abstract concepts and applying them directly to supply networks. For instance, if one considers technical information such as design innovations rather than pricing, then the more such information is communicated, the better performance there will be.

Information exchange links are well documented among Toyota's supply base. The Kyohokai supplier association, coordinated by Toyota, aims to facilitate the exchange of technical know-how and the development of trust among suppliers. During a plant fire, where the facilities of a supplier that produced a key component were destroyed, Kyohokai members played a significant role in reorganizing production and helping Toyota go back to normal levels production in just 9 days (Nishiguchi and Beaudet 1998). As Borgatti and Li point out, it was a lack of structural holes that helped Toyota and its suppliers in the Aisin fire case.

To investigate the impact of structural holes on supply chains, we need to focus on the smallest unit where it can occur: triads. In a triad, in addition to the direct relationship between actors $\mathrm{A}$ and $\mathrm{C}$, and $\mathrm{B}$ and $\mathrm{C}$ there is a relationship between $\mathrm{A}$ and $\mathrm{B}$ that is 


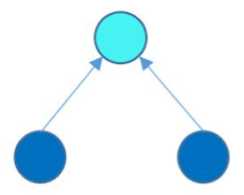

(a) Buyer has competing suppliers

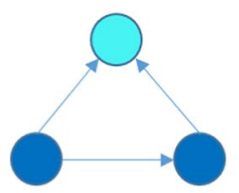

(b) Buyer has coopeting suppliers

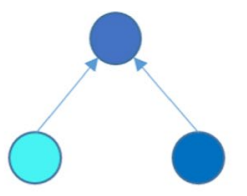

(c) Supplier has a competitor

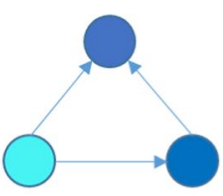

(d) Supplier has a coopetitor

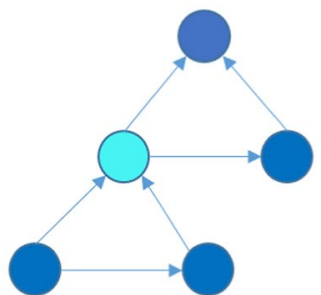

(e) Mid-tier company has co-opeting

suppliers and co-

opetes downstream

Fig. 2 Upstream and downstream triads in a supply network. Light coloured node is the ego while dark coloured nodes are it's alters

derived from their common relationship to actor $\mathrm{C}$. It has been contended that triads are common if the relationships between actors $\mathrm{A}$ and $\mathrm{C}$, and $\mathrm{B}$ and $\mathrm{C}$ are strong. However, if the buyer's relationship with one supplier suffers then the relationship between two suppliers might also suffer (Phillips et al. 1998).

Krackhardt (1998) notes that in a triad, bad action by a firm towards one of its partners results in a poor relationship not only with that partner but also with the other partner. Consequences of bad behaviour such as reputation loss are heightened in triads, thus giving disincentives to act opportunistically. Greve et al. (2010) conclude that triadic structure tends to inflict shared norms of behaviour and serve as constraints against opportunism. While opportunistic behaviour is eliminated, it should be noted that a more constrained firm might become less powerful because it is more dependent on and controlled by its partners (e.g. Gargiulo and Benassi 2000). Greve et al. (2010) found that multiple members of triads are more likely to withdraw from the network (i.e., quitting the supply chain).

There are limited studies on triads in supply networks, and that which exists do not discuss performance effects. Triad studies in supply chains specifically focus on competitive/cooperative relationships between producers of similar goods. An overview of different types of triads in a supply chain is given in Fig. 2.

Several studies advocate that the fostering of supplier dependencies under a single buyer result in innovation and knowledge sharing benefits for all parties involved, positing the existence of triads to be beneficial. Wu and Choi (2005) discussed eight cases where buyers encouraged their suppliers to forge a relationship to share capacity and capability, but several were unsuccessful in achieving this. Dubois and Fredriksson (2008) examined the Volvo-JCI-Lear triad, in which Volvo bought seats from both firms. Over time JCI and Lear developed a reciprocal relationship where they assembled seats for each other and divided seat production among them. In these cases, it was concluded that triads contributed to innovation and efficiency for both the buyer and the two suppliers as a result of operational improvements such as 
lead-time reduction and knowledge exchange (Fig. 2b). Wu and Choi (2005) also note that by pooling their resources, suppliers achieved better flexibility in managing their capacity and capability, which increased operational efficiency and led to more business from the buyer. However, in one of the cases described, the suppliers both had to reduce their prices, making the buyer better off, but losing profit margin themselves (Fig. 2d). (Asanuma 1994) points out that when a new contract is being negotiated, a buyer can bring get the two competing suppliers to collaborate and create the initial broad-based terms of the contract, but then separately negotiate with each supplier for the detailed terms. Two suppliers can be coerced to work together on different projects but are not supposed to compete with each other-as it happened in the case detailed by Wu and Choi (2005).

The opposite case might also occur, where two suppliers with specialised, rare parts work together, and the buyer has no choice but to take the price offer given by the collaborating suppliers. Companies with a weak presence in the market will be unlikely to have the power to make competing suppliers collaborate.

It is also worth noting that triads might also make it more likely that suppliers invest in systems that make coordination easier. These could include compatible information and logistical systems, and common quality standards, which eliminate non-valueadded transaction activities and may lead to better performance.

Toyota is known for developing close and reciprocal relationships with suppliers. It is therefore not unreasonable to hypothesize that triads in Toyota's supply base will be prominent.

As it has been previously shown, multi-sourcing activities result in increased performance and reduced risk for the buying firm. Hence, we also expect a positive relationship between the number of competing suppliers and the buyer's performance, even if they do not link with one another. The question therefore posed is whether the linking of competing suppliers (i.e. co-opetition) will result in increased performance for the buying firm. Similarly,do the supplying firms involved in triads fare better than those who do not link with their competitors?

Given the above arguments, we expect that co-opeting suppliers will result in better performance for the firm than competing suppliers, although both will impact performance positively.

Hypothesis 3 The number of closed triads a supplier is involved in, has a positive impact on its performance.

In a supply network, the mid-tier firms experience both upstream and downstream structural choices. The combined effect may be different for firms that are at the top tier and only experience upstream structural holes as a buyer. The complexity of the supply network may significantly increase with more numbers of upstream and downstream triadic relationships (Fig. 2e), making these firms unable to gain returns from triads due to operational burden (Bozarth et al. 2009).

Hypothesis 4 Participation in both upstream and downstream triads will increase complexity and negatively influence firm performance. 


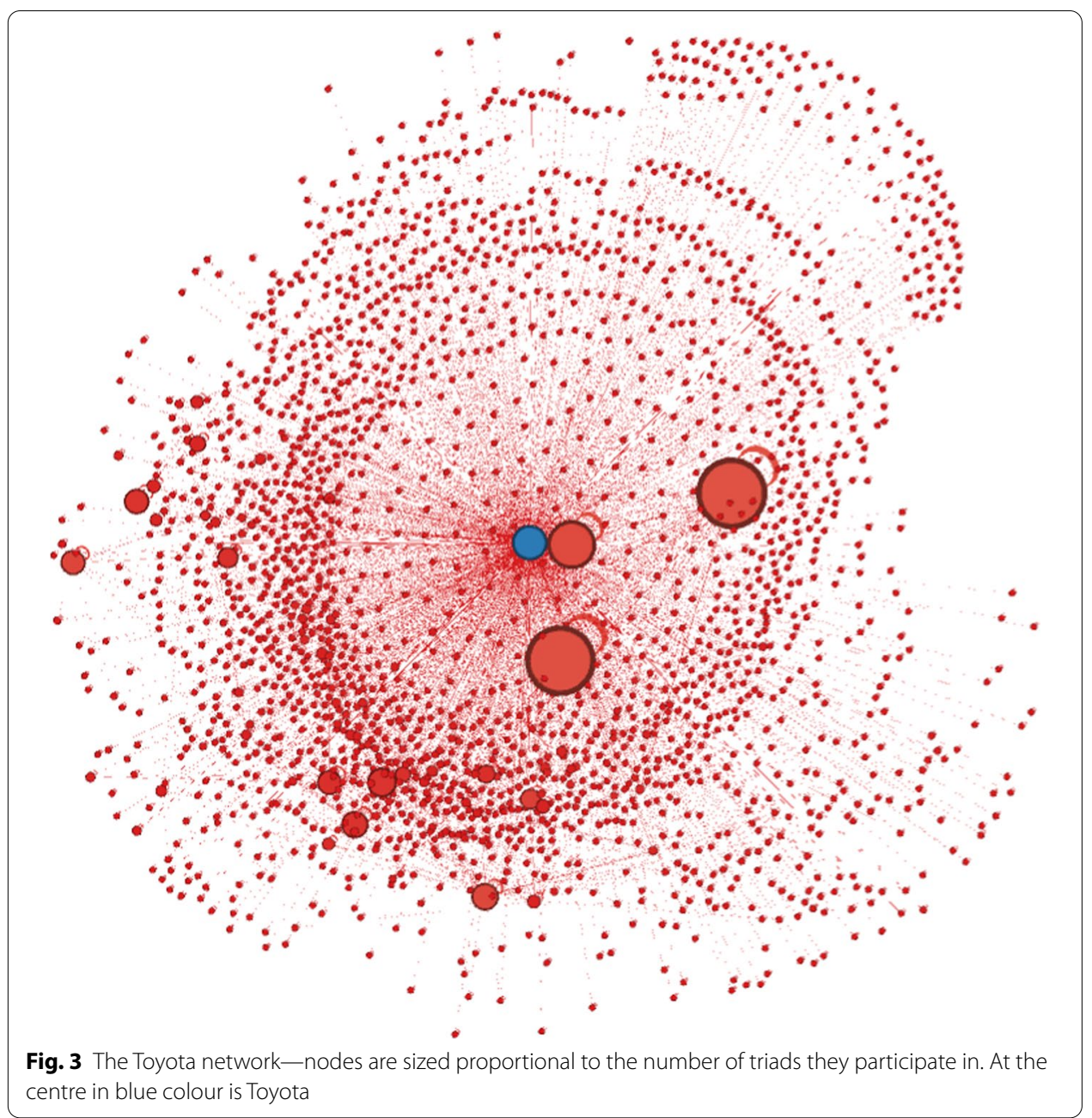

\section{Methods}

\section{Research design and data collection}

To test the hypotheses put forward we construct a large-scale supply network map and investigate the performance effects of network position. Figure 3 displays the network under study.

The network is a directed graph involving 2120 nodes and 4756 links. The average degree is 4.5, with an average path length of 2.01. Applying the Blondel et al. (2008) algorithm reveals 8 communities. The network does not contain any cycles and has a clustering coefficient of 0.06 .

The firm-level data obtained contains firm identification, the number of employees, suppliers, and clients, product categories offered, and the location of its production facility. Product categories consist of 934 standard categories used by the industry and do not include detailed model numbers or custom-made products. As such, network measures that incorporate product data such as competitive and cooperative triads are suggestive and not definitive. A sample of categories is given in the appendix.

Following data collection, we undertook a validation activity by sampling random suppliers from the network and querying their supplier and client relationships in 
CapitalIQ ${ }^{3}$ database. The inter-resource reliability is 0.71 , thus above the recommended level (Cohen et al., 2003).

Following validation of the network map, we carried out data sampling to test performance effects on a sub-set of companies. This was done by randomly selecting 150 firms from the dataset, based on the constraint that the selected firm has both in and out links so that metrics could be appropriately applied. We then gathered performance data for the sampled firms from the OneSource database. A second query was undertaken by a cross-validating reported performance with company website reports. Interresource reliability at this stage was found to be 0.87 , and thus above the recommended level (Cohen et al., 2003). We compared the means of the sample with those of the whole population of firms belonging to the network using the two-sided Kolmogorov-Smirnov (KS) test. The advantage of using the KS test is that it is non-parametric, i.e. it makes no strong a priori assumptions regarding the form of the distributions. The results of the test revealed that the distribution of the drawn sample is not statistically significantly different from that of the whole population, which helps further enhance our confidence in the representativeness of the drawn samples.

Following data sampling and performance queries, we carried out a generalized least squares (GLS) linear multiple regression analysis to relate network measures to performance. Since some measures proposed were found to be correlated, we employed the Least Absolute Shrinkage and Selection Operator (LASSO) regression analysis where multicollinearity was of concern. In what follows we present our models.

\section{Regression variables}

Performance (PERF)

Firm performance measures how well a firm fulfils its financial goals. In this study $y_{2}$ we proxied overall firm performance using total annual revenues (REV), net profit (NP) and labour productivity (PROD). Also, we performed a robustness analysis by using different measures of performance including Net Income, EBITDA, and Total Enterprise Value (TEV), for a smaller subset of the data sample, which showed consistency with our results (please see "Appendix A"). These measures have been widely used in previous researches as these represent primary indicators of performance for most stakeholders (Chen and Paulraj, 2004).

Using revenues as a performance metric may be effective as the majority of the sample firms have headquarters in Japan (91\%). All revenue data were converted into U.S. dollars corresponding to the same historic dollar value.

In addition to financial performance, we investigated labour productivity, proxied as sales per employee. Productivity is defined as the ratio of output to input. This measure is often used as a measure of operational performance in supply chains (Schmenner and Swink 1998), because it relates to operational efficiency and allows a standard index to be generated. It should be noted that productivity is not the same as profitability, as a firm can attempt to optimise its productivity but can incur external cost factors that deem it unprofitable.

\footnotetext{
www.capitaliq.com
} 


\section{Supply network centrality (SNC)}

We proxied the number of business paths that flow through a firm in the network by counting the total number of downstream paths that pass through the firm, formally defined as:

Let $A_{i j}$ be an adjacency matrix with elements:

$$
A_{i j}=\left\{\begin{array}{l}
1 \text { if there is an edge from } j \text { to } i \\
0 \text { otherwise }
\end{array}\right.
$$

Let us consider $i$ to be the top assembler-Toyota. Then the product $A_{i k} A_{k j}$ is 1 if there is a path length 2 from $j$ to $i$ via $k$, and 0 otherwise. The total number of paths of length 2 from $j$ to $i$ via any other node is:

$$
M_{i j}=\sum_{k=1}^{N} A_{i k} A_{k j}=\left[A^{2}\right]_{i j}
$$

where $[. .]_{i j}$ denotes the $i j$ th element of a matrix.

Similarly, the product $A_{i k} A_{k j}$ is 1 if there is a path length of 3 from $j$ to $i$ via $l$ and $k$, and 0 otherwise. Hence the total number of path lengths of 3 is $\left[A^{3}\right]_{i j}$. Generalising to paths of arbitrary length $l$, we find that $M_{i j}^{l}=\left[A^{l}\right]_{i j}$, where $M_{i j}^{l}$ is the total number of path lengths of $l$ from $j$ to $i$.

To measure the supply network centrality of a given node $j$, we consider the total number of chains that pass from that node to Toyota, given by:

$$
S N C_{j}=\sum_{l=1}^{L} \sum_{i=1}^{N}\left[M^{l}\right]_{i j},
$$

where $L$ is the maximum path length, and $N$ is the total number of nodes.

\section{Tier position}

We assign every firm a tier level by calculating the mean path length to the top tier assembler firm (which is Toyota in this case), where a path length denotes the number of links that exist between a firm and Toyota. Using the path length formalisation previously described:

$$
\sum_{l=1}^{L}\left[M^{l}\right]_{i j}
$$

denotes the total number of paths connecting node $j$ to Toyota. If we multiply the total number of given path lengths for node $j$ with their respective lengths $l$, and divide by the total number of path lengths in which node $j$ participates, we find the average path length SNTL of node $j$ in the networks (SNTL1):

$$
\operatorname{SNTL}_{j}=\frac{\sum_{l=1}^{L}\left[M^{l}\right]_{i j} \times l}{\sum_{l=1}^{L}\left[M^{l}\right]_{i j}}
$$


where $L$ is the longest path length in the supply network, $i$ is Toyota (the focal firm), and $j$ is the supply firm in question.

To make the analysis more robust we repeated the same analysis with the most frequently occurring path length to Toyota (SNTL2). When there were equal frequencies, we took a conservative approach and chose the shortest path, as our null hypothesis is that a longer chain will impact performance negatively. The second approach is defined as the mode of $\sum_{l=1}^{L}\left[M^{l}\right]_{i j}$.

\section{Triads}

We define competing firms as those that supply to the same client and have at least one overlapping product in their portfolio, whereas co-opeting firms are those that compete but supply to one another at the same time.

The following measures are then taken to evaluate the firm's triads:

BSH (Buyer's Structural Hole): Number of competing suppliers firm has as a buyer (Fig. 2a).

BT (Buyer's Triad): Number of co-co-opetitors a supplier has (Fig. 2b).

SSH (Supplier's Structural Hole): Number of competitors a supplier has (Fig. 2c).

ST (Supplier's Triad): Number of co-opetitors firms has as a supplier (Fig. 2d). It is worth noting that there are firms that are coopeting and that are both exchanging goods to each other (A and B supply to C, A supplies to B, and B supplies to A).

In addition, we calculated interaction effects for firms acting as both buyers and suppliers:

BT $\times$ ST (Fig. 2e).

We also included control variables that are considered to be correlated with performance to test the additional explanatory power of network variables in our model:

\section{Firm age (AGE)}

Older firms tend to introduce more innovations, albeit incremental ones (Sørensen and Stuart, 2000). Research suggests that over time, firms also establish routines and surmount the burden of newness, which potentially helps in enhanced performance and probability of survival. In this study, firm age was calculated as the time elapsed between a firm's founding date and the year of data collection. The average firm in the sample was 68 years old.

\section{Employees (SIZE)}

In the calculation for firm performance, we employed the number of employers as a control for firm size, commonly used in high-technology industries (Sørensen and Stuart 2000). An average firm in our dataset comprised about 3164 employees.

Japanese firm (JAP)

To control for institutional differences, we employed a dummy variable to distinguish between Japanese and non-Japanese companies ( 1 = Japanese firm), using the location of a firm's headquarters. In our sample, 91 percent of the firms had headquarters in Japan. 


\section{Public firm (PUB)}

To control for the ownership status of the firm, we employed a dummy variable to distinguish between public and private firms ( $1=$ public firms). In our sample, 80 percent of the firms were public.

\section{Direct links to Toyota (DL)}

In "Data and hypothesis" section we reviewed Toyota's Keiretsu structure, and how Toyota might take steps to intervene in the operational management of its suppliers through a shared-ownership frame. While it is argued that long-term stable relationships generated by the Keiretsu and operational interventions might lead to lower costs, others posit that any returns on operational efficiencies and are augmented by the lower price offerings to Toyota. Recent investigations also question the very existence of Keiretsu today. We thus control for the impact of a potential Keiretsu style management by introducing a binary variable that distinguishes between those firms that have a direct supply link to Toyota, and those that do not.

\section{Estimation procedure}

We employed generalized least square (GLS) regression analysis, as it provides more efficient parameter estimates compared to a linear regression model by minimising the weighted sum of squared residuals (Greene 2012). Estimates obtained from GLS are corrected for autocorrelation and cross-section heteroscedasticity. Some of the hypotheses indicate the inclusion of interaction terms, either as cross-products of the same variable to create squared terms to assess the potential for diminishing returns (Hypotheses 1) or as linear cross-products of two different variables (Hypothesis 4).

To test moderated regression models, we need to include both direct and interaction effects. It has, however, been pointed out that this approach is a somewhat conservative approach for examining interaction effects because the statistical significance of the interaction term is assessed once all lower-order effects have been controlled (Jaccardet al. 1990).

To improve the interpretability of the regression models and to tackle potential multicollinearity, independent variables were standardised (Cohen et al. 2003). This standardisation makes it possible to compare coefficients of different variables with different scales, without compromising on the quality of data nor affecting the statistical significance. Variables used to create interaction terms via cross-multiplication were standardised beforehand. To detect multicollinearity, we computed the variance inflation factors (VIF) for each coefficient. Encouragingly, the maximum estimated VIF for all direct effects across the three different dependent variables was 3.47, which was well below the recommended upper limit of 10 (Cohen et al. 2003).

The VIFs for the interaction terms were however slightly higher (17.54 for Model 4, 13.65 for Model 7), which is somewhat expected as the interaction terms were created as linear cross-product of two variables. Multicollinearity can result in inflated standard errors associated with parameter estimates, which results in reduced power to identify the statistically significant variables in a regression model. The overall model fit or predictive power, however, is not influenced due to multicollinearity (Kennedy 1996). For 
Table 1 Linear regression equations

\begin{tabular}{|c|c|}
\hline Model number & Model \\
\hline Model 1 (Base Model 1) & $P E R F=a_{1}+a_{2}(S N T L 1)+a_{3}(A G E)+a_{4}(S I Z E)+a_{5}(P \cup B)+a_{6}(J A P)+a_{7}(D L)+e$ \\
\hline Model 2 & $P E R F=a_{1}+a_{2}\left(\right.$ SNTL1) $+a_{3}($ SNC $)+a_{4}($ AGE $)+a_{5}($ SIZE $)+a_{5}(P U B)+a_{6}(J A P)+a_{7}(D L)+e$ \\
\hline Model 3 & $P E R F=a_{1}+a_{2}\left(\right.$ SNTL2) $+a_{3}($ SNC $)+a_{4}($ AGE $)+a_{5}($ SIZE $)+a_{5}(P \cup B)+a_{6}(J A P)+a_{7}(D L)+e$ \\
\hline Model 4 & $\begin{array}{l}P E R F=a_{1}+a_{2}(S N T L 1)+a_{3}(S N C)+a_{4}\left(S N C^{2}\right)+a_{5}(A G E)+a_{6}(S I Z E)+a_{7}(P U B)+e \\
+a_{8}(J A P)+a_{9}(D L)+e\end{array}$ \\
\hline Model 5 & $\begin{array}{l}\text { PERF }=a_{1}+a_{2}\left(\text { SNTL1) }+a_{3}(S T)+a_{4}(S S H)+a_{5}(\text { AGE })+a_{6}(\text { SIZE })+a_{7}(P U B)\right. \\
+a_{8}(J A P)+a_{9}(D L)+e\end{array}$ \\
\hline Model 6 & $\begin{array}{l}\text { PERF }=a_{1}+a_{2}\left(\text { SNTL1) }+a_{3}(B T)+a_{4}(B S H)+a_{5}(\text { AGE })+a_{6}(\text { SIZE })+a_{7}(P U B)\right. \\
+a_{8}(J A P)+a_{9}(D L)+e\end{array}$ \\
\hline Model 7 & $\begin{array}{l}P E R F=a_{1}+a_{2}(S N T L 1)+a_{3}(B T)+a_{4}(S T)+a_{5}(B T X S T)+a_{6}(A G E)+a_{7}(S I Z E) \\
+a_{8}(P \cup B)+a_{9}(J A P)+a_{10}(D L)+e\end{array}$ \\
\hline Model 8 (Base Model 2) & $\begin{array}{l}\text { PERF }=a_{1}+a_{2}\left(\text { SNTL1) }+a_{3}(\mathrm{SNC})+a_{4}(\mathrm{BT})+a_{5}(\mathrm{BSH})+a_{6}(\mathrm{ST})+a_{6}(\mathrm{SSH})\right. \\
+a_{7}(\mathrm{AGE})+a_{8}(\mathrm{PUB})+a_{9}(\mathrm{JAP})+a_{10}(\mathrm{DL})+e\end{array}$ \\
\hline
\end{tabular}

the GLS regression results presented below, most of the interaction terms and transformed variables (we used squared transformation) are statistically significant. Encouragingly, as presented in "Discussion" section, the regression coefficients across different models are overall consistent in sign and broadly in magnitude.

Given the existence of multicollinearity, we added a further robustness check with Lasso (Least Absolute Shrinkage and Selection Operator) regression, a specifically designed technique that tackles multicollinearity by penalizing collinear variables. The results of which aligned with the output obtained through GLS regression for Models 2-7 ("Appendix A"). We obtained further insight by using factor analysis, the results of which are reported in "Appendix B".

Table 1 describes the linear regression equations for the different models we consider in this study. To avoid loss of interpretability due to presence of multicollinearity, we carried out the analysis by taking into account 8 different models (Table 1), whereby each model was formed using a different combination of variables.

\section{Results}

Table 2 presents descriptive statistics, Table 3 presents the bivariate correlation among the variables, Tables 4, 5 and 6 provides GLS regression results. The firm with most structural holes as a buyer in Toyota's network is JTEKT, whereas the maximum number of triads belongs to Toyota Boshoku, a supplier that belongs to the Toyota Group. The firm with the most competing suppliers is Thai NOK, and the firm, which cooperates with its competitors most is Toyoda Gosei, part of the Toyota group.

All explanatory variables vary considerably. Majority of firms are in Japan and dataset contains both small medium enterprises to large conglomerates. There is high correlation between the SNC metric and triad measures (for instance 0.85 correlation between SNC and ST), and between buyers' structural holes and suppliers' structural holes. Expectedly the same is true for the interaction terms.

We use a model comprising only the control variables (Model 1) as a baseline model. All models employed to test the hypotheses achieve a statistically significant improvement over the baseline model ( $p<0.001$ in all cases). Similarly, we estimated a second baseline model (Model 8 ) that contained all control variables as well as all 
Table 2 Descriptive statistics

\begin{tabular}{llrll}
\hline & Mean & \multicolumn{1}{c}{ S.D } & Min & Max \\
\hline REV & 2386.27 & 2852.48 & 59.00 & $14,328.00$ \\
PROD & 1.21 & 1.70 & 0.15 & 13.51 \\
NP & 640.66 & 1562.34 & 17.9 & 11.304 \\
SNTL1 & 1.52 & 0.56 & 0.75 & 5.70 \\
SNTL2 & 2 & 1.7 & 1 & 7 \\
SNC & 285.23 & 568.04 & 3.00 & 3508.00 \\
ST & 39.47 & 75.68 & 0.00 & 532.00 \\
SSH & 230.22 & 198.37 & 0.00 & 1463.00 \\
BT & 2.09 & 7.65 & 0.00 & 56.00 \\
BSH & 68.17 & 197.87 & 0.00 & 1786.00 \\
AGE & 71.58 & 10.247 .34 & 4.00 & 157.00 \\
SIZE & 3164.00 & 0.17 & 205.00 & $106,244.00$ \\
PUB & 0.97 & 0.26 & 0 & 1 \\
JAP & 0.93 & 0.45 & 0 & 1 \\
DL & 0.71 & 0 & 1 \\
\hline
\end{tabular}

Statistics are shown on data prior to standardization. Regression analysis has been carried out on standardized data, hence variables have mean 0 , and standard deviation of 1

the network variables we would like to investigate. Model 8 shows the maximum coefficient of determination $\left(R^{2}\right)$ that can be achieved (as shown in Table 4), as it includes all variables considered in this study. As expected, for Model 8, due to the existence of multicollinearity among variables (as quantified using VIF), the error terms are high and the significance of variables is inconsistent when compared to other models that are formed using a subset of less inter-correlated variables.

In Hypothesis 1, we stated that the number of paths which pass through a firm in a supply network will have a positive effect on the performance of the firm. Further, we postulated that this relationship will be characterised by diminishing returns, and hence, the relationship is inverted U-shaped. Model 4 contains the linear SNC term along with the squared term of the same metric to assess the hypothesis. Model 4 does not contain other metrics such as buyers' and suppliers' structural holes, as the centrality metric is highly correlated with them, and would make the results uninterpretable due to multicollinearity. The results in Model 4 provide support for Hypothesis 1 because the linear term of SNC is positive and statistically significant $(p<0.01)$, whereas the squared term of the same metric is negative and statistically significant $(p<0.05)$. These findings are consistent with models that include Net Profit and Productivity as dependent variables (Tables 5 and 6 , respectively).

To determine the optimal number of paths a firm can sustain without its returns being diminished, for instance in terms of Total Revenue, we calculate the absolute value of the partial derivative with respect to SNC $(0.34174 /(2 \times 0.194)=0.880)$. We know that this is a maximum in the function ${ }_{2}$ which relates $\mathrm{SNC}$ to revenues. We need to transform variables to their original values as we standardised them before we carried out the regression analysis. As the standardised optimum is a $\mathrm{z}$-score, we transform it back by multiplying with standard deviation and adding to the mean, finding: 


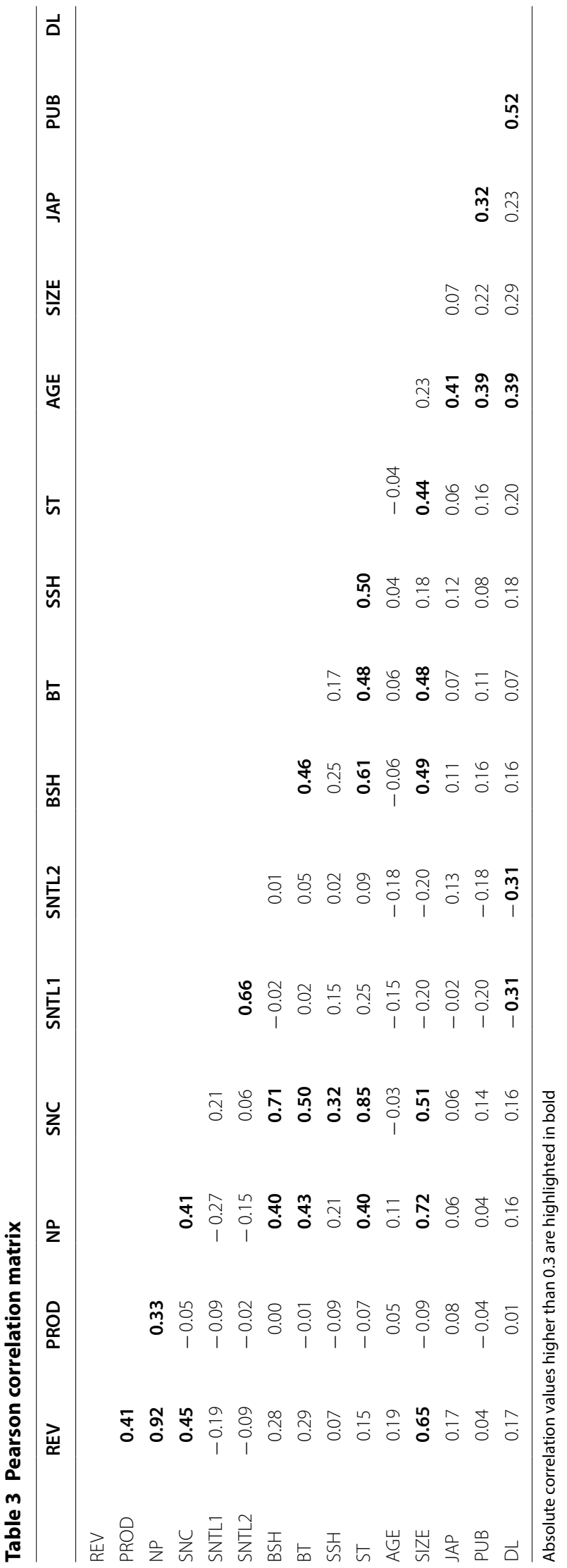


Table 4 GLS Regression results-total annual revenue

\begin{tabular}{|c|c|c|c|c|c|c|c|c|}
\hline & \multicolumn{8}{|c|}{ Standardized estimate-dependent variables: REV } \\
\hline & $\begin{array}{l}\text { Model } \\
1 \text { (Base } \\
\text { Model 1) }\end{array}$ & Model 2 & Model 3 & Model 4 & Model 5 & Model 6 & Model 7 & $\begin{array}{l}\text { Model } 8 \\
\text { (Base Mode } \\
\text { 2) }\end{array}$ \\
\hline Intercept & 0.002 & -0.002 & -0.811 & -0.011 & -0.003 & -0.001 & 0.878 & $1.002^{* *}$ \\
\hline \multicolumn{9}{|l|}{$\begin{array}{l}\text { Independ- } \\
\text { ent vari- } \\
\text { ables }\end{array}$} \\
\hline SNTL1 & & $-0.254^{* *}$ & & $-0.244^{* *}$ & $-0.289^{* *}$ & $-0.206^{* *}$ & $-0.193^{* *}$ & $-0.175^{*}$ \\
\hline SNTL2 & & & $-0.195^{* *}$ & & & & & \\
\hline SNC & & $0.422^{* * *}$ & $0.366^{* * *}$ & $0.342^{* *}$ & & & & $1.881^{* * *}$ \\
\hline$(\mathrm{SNC})^{2}$ & & & & $-0.194^{*}$ & & & & \\
\hline ST & & & & & $0.408^{* * *}$ & & $0.343^{*}$ & 0.124 \\
\hline SSH & & & & & 0.094 & & & -0.003 \\
\hline BT & & & & & & $0.425^{* * *}$ & $0.490^{*}$ & 0.197 \\
\hline BSH & & & & & & $0.167^{*}$ & & $1.953^{* * *}$ \\
\hline $\mathrm{ST} \times \mathrm{BT}$ & & & & & & & -0.481 & \\
\hline \multicolumn{9}{|l|}{$\begin{array}{c}\text { Control } \\
\text { vari- } \\
\text { ables }\end{array}$} \\
\hline AGE & $0.186^{*}$ & $0.248^{* *}$ & $0.128^{* *}$ & $0.286^{* *}$ & $0.241^{* *}$ & $0.292^{* *}$ & $0.118^{* *}$ & $0.176^{*}$ \\
\hline SIZE & $0.270^{* *}$ & $0.174^{*}$ & $0.256^{* *}$ & $0.174^{*}$ & $0.185^{*}$ & $0.138^{*}$ & $0.229^{*}$ & $0.177^{*}$ \\
\hline PUB & 0.001 & 0.048 & 0.054 & 0.045 & 0.035 & 0.020 & 0.056 & $1.590^{* *}$ \\
\hline JAP & 0.123 & 0.06 & 0.718 & 0.032 & 0.07 & 0.06 & 0.662 & 0.558 \\
\hline $\mathrm{DL}$ & 0.076 & 0.058 & 0.187 & 0.092 & 0.0823 & 0.333 & 0.022 & 0.003 \\
\hline$R^{2}$ & 0.16 & 0.39 & 0.40 & 0.43 & 0.42 & 0.46 & 0.42 & 0.50 \\
\hline $\begin{array}{l}\text { Adjusted } \\
R^{2}\end{array}$ & 0.13 & 0.35 & 0.37 & 0.39 & 0.38 & 0.42 & 0.37 & 0.46 \\
\hline $\mathrm{F}$ & 5.05 & 10.63 & 12.47 & 9.53 & 10.44 & 12.18 & 9.71 & 11.04 \\
\hline$p$ value & $9.23 e-04$ & $3.818 \mathrm{e}-09$ & $1.061 \mathrm{e}-10$ & $1.023 e-09$ & $8.323 e-10$ & $3.387 e-11$ & $4.219 e-10$ & $9.934 \mathrm{e}-13$ \\
\hline $\begin{array}{l}\text { Improve- } \\
\text { ment } \\
\text { over } \\
\text { base } \mathrm{R}^{2}\end{array}$ & & 0.22 & 0.23 & 0.27 & 0.26 & 0.29 & 0.25 & 0.34 \\
\hline Max VIF & 1.38 & 1.38 & 1.38 & 17.54 & 1.41 & 3.47 & 13.65 & 50.87 \\
\hline
\end{tabular}

$$
\begin{aligned}
& X=\text { mean }+ \text { standard deviation } \mathrm{z}-\text { score, or } \\
& X=285.24+(566.03 \times 0.880)=785.54
\end{aligned}
$$

Therefore, the average firm in this network will reach its optimum flow handling capacity when attempting to channel about 786 paths in the network. Note that the value is quite high, as we are not merely counting the links a firm has; but taking into account also the links that a firm's suppliers have, and links the suppliers' suppliers have and so on. Besides, the value should be taken as suggestive as it is contextdependent in terms of the underlying sample and period studied.

In Hypothesis 2, we asserted that a firm's supply network tier level and its performance will have an inverse relationship in that the higher the average tier level of a firm, the worse its performance will be because the firm is further away from the focal firm. In Model 2 we insert the SNTL1 term to assess this hypothesis. The statistically significant negative term $(p<0.01)$ indicates that firms with a longer path to Toyota 
Table 5 GLS regression results-net profit

\begin{tabular}{|c|c|c|c|c|c|c|c|c|}
\hline & Standar & ized estimat & -dependen & ariable: NP & & & & \\
\hline & $\begin{array}{l}\text { Model } \\
1 \text { (Base } \\
\text { Model } \\
1)\end{array}$ & Model 2 & Model 3 & Model 4 & Model 5 & Model 6 & Model 7 & $\begin{array}{l}\text { Model } 8 \\
\text { (Base Mode } \\
\text { 2) }\end{array}$ \\
\hline Intercept & -0.009 & -0.0043 & -0.811 & -0.043 & -0.079 & -0.084 & -0.085 & $1.002^{* *}$ \\
\hline $\begin{array}{l}\text { Independ- } \\
\text { ent vari- } \\
\text { ables }\end{array}$ & & & & & & & & \\
\hline SNTL1 & & $-0.213^{*}$ & & $-0.213^{*}$ & $-0.224^{*}$ & $-0.205^{*}$ & $-0.210^{* *}$ & $-0.205^{*}$ \\
\hline SNTL2 & & & $-0.112^{*}$ & & & & & \\
\hline SNC & & $0.708^{* * *}$ & $0.655^{*}$ & $0.709^{* *}$ & & & & $0.802^{*}$ \\
\hline$(\mathrm{SNC})^{2}$ & & & & -0.907 & & & & \\
\hline ST & & & & & $0.721^{* * *}$ & & 0.088 & 0.434 \\
\hline SSH & & & & & 0.065 & & & 0.031 \\
\hline BT & & & & & & $0.541^{*}$ & $0.551^{*}$ & 0.505 \\
\hline BSH & & & & & & 0.178 & & 0.170 \\
\hline $\mathrm{ST} \times \mathrm{BT}$ & & & & & & & -0.082 & \\
\hline $\begin{array}{c}\text { Control } \\
\text { vari- } \\
\text { ables }\end{array}$ & & & & & & & & \\
\hline AGE & 0.054 & 0.097 & 0.008 & 0.097 & 0.094 & 0.078 & 0.078 & 0.077 \\
\hline SIZE & & 0.328 & 0.277 & $0.159^{*}$ & $0.100^{*}$ & $0.309^{*}$ & $0.441^{*}$ & $0.274^{*}$ \\
\hline PUB & -0.285 & 0.182 & 0.054 & 0.181 & 0.033 & 0.293 & 0.294 & 0.322 \\
\hline JAP & 0.410 & -0.118 & 0.718 & -0.118 & -0.101 & -0.104 & -0.105 & -0.100 \\
\hline $\mathrm{DL}$ & 0.0039 & 0.001 & 0.123 & 0.082 & 0.091 & 0.003 & 0.012 & 0.003 \\
\hline$R^{2}$ & 0.02 & 0.59 & 0.40 & 0.54 & 0.53 & 0.56 & 0.56 & 0.61 \\
\hline $\begin{array}{l}\text { Adjusted } \\
R^{2}\end{array}$ & 0.01 & 0.55 & 0.37 & 0.51 & 0.52 & 0.55 & 0.55 & 0.55 \\
\hline $\mathrm{F}$ & 0.2 & 15.30 & 12.47 & 9.53 & 14 & 15.99 & 13.48 & 10.05 \\
\hline$p$ value & 0.9 & $1.002 \mathrm{e}-10$ & $1.061 \mathrm{e}-10$ & $1.023 e-09$ & $4.7833 e-10$ & $4.531 \mathrm{e}-11$ & $1.94 \mathrm{e}-10$ & $1.506 \mathrm{e}-10$ \\
\hline $\begin{array}{l}\text { Improve- } \\
\text { ment } \\
\text { over } \\
\text { base } \mathrm{R}^{2}\end{array}$ & & 0.57 & 0.38 & 0.52 & 0.51 & 0.54 & 0.54 & 0.59 \\
\hline Max VIF & 1.02 & 1.36 & 1.56 & 24.59 & 1.58 & 9.98 & 16.12 & 84.62 \\
\hline
\end{tabular}

will perform worse than firms that are closer, all else being equal. This finding seems to be robust because the SNTL2 metric, which took the frequency of tier levels into account rather than the mean, yields similar results in Model 3. As with hypothesis 1, our findings here are consistent with other explanatory models.

In Hypothesis 3, we suggested that participation in a closed, co-opetitive triad would be beneficial, and participation in the same types of triads in both directions would have a negative effect due to increased complexity. To test this hypothesis, in Model 5 we inserted the number of structural holes (SSH) (i.e. lack of a triad) and triads (ST) a firm has as a supplier, and in Model 6 we inserted the number of structural holes (BSH) and triads (BT) a firm has as a buyer. There is a high correlation between the BSH variable and other structural holes/triad variables, and hence, we refrained from inserting all these variables into one model, which would make results uninterpretable. When explaining total annual revenues, terms associated with structural triads are significant $(p<0.001)$ and positive, as well as being higher than terms associated with structural 
Table 6 GLS regression results-productivity

\begin{tabular}{|c|c|c|c|c|c|c|c|c|}
\hline & Standardis & d estimate- & lependent va & able: produ & vity & & & \\
\hline & $\begin{array}{l}\text { Model } \\
1 \text { (Base } \\
\text { Model 1) }\end{array}$ & Model 2 & Model 3 & Model 4 & Model 5 & Model 6 & Model 7 & $\begin{array}{l}\text { Model } \\
8 \text { (Base } \\
\text { Model 2) }\end{array}$ \\
\hline Intercept & -0.087 & -0.008 & -0.982 & -0.731 & -0.786 & -0.714 & 0.785 & -0.755 \\
\hline $\begin{array}{l}\text { Independ- } \\
\text { ent vari- } \\
\text { ables }\end{array}$ & & & & & & & & \\
\hline SNTL1 & & $-0.477^{* * *}$ & & $-0.255^{* * *}$ & $-0.266^{* *}$ & $-0.329^{* * *}$ & $-0.224^{* * *}$ & $-1.362^{* * *}$ \\
\hline SNTL2 & & & $-0.654^{* *}$ & & & & & \\
\hline SNC & & $0.162^{*}$ & $0.908^{*}$ & $0.127^{*}$ & & & & $0.829^{*}$ \\
\hline$(\mathrm{SNC})^{2}$ & & & & $-0.436^{* *}$ & & & & \\
\hline ST & & & & & $0.453^{* * *}$ & & 0.033 & 0.002 \\
\hline SSH & & & & & -0.040 & & & -0.179 \\
\hline BT & & & & & & $0.819^{* * *}$ & 0.085 & $0.501^{*}$ \\
\hline BSH & & & & & & $-0.314^{*}$ & & $-0.89^{* * *}$ \\
\hline $\mathrm{ST} \times \mathrm{BT}$ & & & & & & & -0.438 & \\
\hline $\begin{array}{l}\text { Control } \\
\text { variables }\end{array}$ & & & & & & & & \\
\hline AGE & $0.212^{*}$ & 0.121 & $0.128^{* *}$ & 0.002 & $0.008^{* *}$ & $0.002^{* *}$ & 0.007 & 0.010 \\
\hline PUB & $-0.205^{*}$ & $-0.292^{*}$ & 0.054 & 0.754 & 0.811 & $0.163^{*}$ & $0.182^{*}$ & $0.016^{* *}$ \\
\hline JAP & 0.257 & 0.098 & 0.718 & 0.003 & 0.001 & 0.009 & 0.811 & 0.779 \\
\hline $\mathrm{DL}$ & & & & & & & & \\
\hline$R^{2}$ & 0.11 & 0.28 & 0.40 & 0.28 & 0.39 & 0.38 & 0.32 & 0.48 \\
\hline $\begin{array}{l}\text { Adjusted } \\
\mathrm{R}^{2}\end{array}$ & 0.09 & 0.27 & 0.37 & 0.29 & 0.38 & 0.37 & 0.30 & 0.47 \\
\hline $\mathrm{F}$ & 5.019 & 10.01 & 12.47 & 17.17 & 18.44 & 16.87 & 16.39 & 25.04 \\
\hline$p$ value & $7.91 e-04$ & $2.70 e-09$ & $1.061 \mathrm{e}-10$ & $<2.2 \mathrm{e}-16$ & $<2.2 \mathrm{e}-16$ & $<2.2 \mathrm{e}-16$ & $<2.2 \mathrm{e}-16$ & $<2.2 \mathrm{e}-16$ \\
\hline $\begin{array}{l}\text { Improve- } \\
\text { ment } \\
\text { over } \\
\text { base } \mathrm{R}^{2}\end{array}$ & & 0.17 & 0.29 & 0.17 & 0.28 & 0.27 & 0.21 & 0.37 \\
\hline Max VIF & 4.01 & 4.33 & 1.38 & 4.19 & 4.58 & 9.31 & 34.39 & 93.83 \\
\hline
\end{tabular}

holes (Table 4, Models 5 and 6). This result suggests that participation in co-opetitive triads bring higher revenues to both the buyers and the suppliers. Also, Model 6 resulted in the closest $\mathrm{R}$ square to that of the second base model (Model 8) where we included all explanatory variables, meaning that the buyers' structural holes (BSH) and buyers' triads (BT) have higher explanatory and predictive power than other explanatory models we have used so far. We find the same result when explaining net profit. However, both buyer/supplier structural holes have a negative relationship with productivity. Competing suppliers result in higher returns for the buyer but increased embeddedness i.e., closed, co-opetitive triads result in productivity gains. Thus, we fail to find adequate support for Hypothesis 3 , as different performance measures are impacted differently by the independent variables.

We test our Hypothesis 4 with Model 7. We suggested that while participation in both upstream and downstream structural triads would increase complexity and provide negative returns. To test this hypothesis, we inserted the interaction terms to assess the simultaneous effect of closing both downstream and upstream holes on the performance of the firm. The statistically significant positive terms in both upstream triads and 


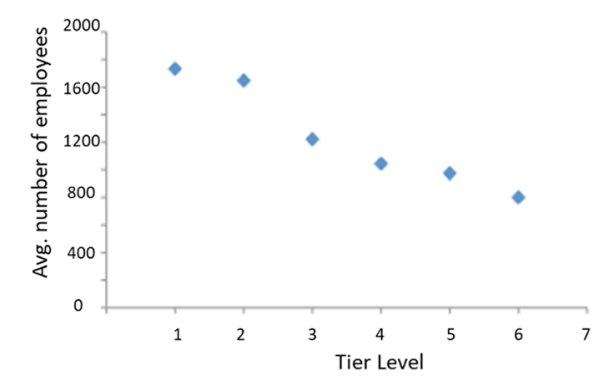

Fig. 4 The average number of employees and links versus tier level

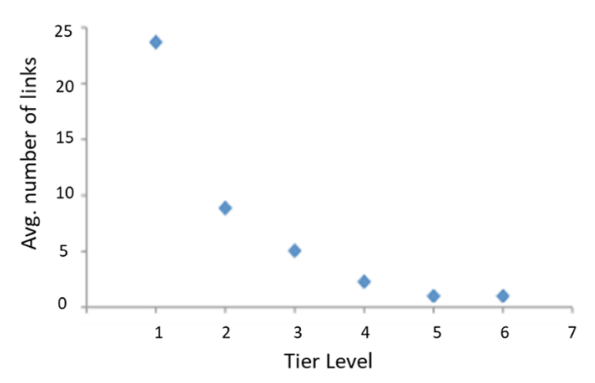

downstream triads contrast with the statistically significant interaction terms between the two variables $(p<0.001)$. This result indicates that firms pursuing triads in both directions tend to have worse performance. Thus, while closed, co-opetitive triads affect performance positively when pursued individually, they lack a synergetic effect when pursued together (both multiple upstream or downstream coopetion) and instead harm performance. The results are consistent across all dependent variables. Hence we find support for Hypothesis 4.

\section{Discussion}

Scholars in supply chain research are increasingly questioning the performance effects of network embeddedness. In this work we related theoretical arguments that explain network positioning to firm performance, by sampling firms from a large-scale automotive supply network, devising measures to extract their network position and relating these measures to their performance.

Our results provide strong evidence for network effects on focal firm (i.e., Toyota's) performance and confirm what has been suggested in the literature: firms should be careful where and how they position themselves in the supply chain.

The analysis suggests that firms exist on many tier levels, some of which more frequent than others. When we take the mean tier level, we find that the focal form the supplier is, the smaller performance it seems to obtain. This analysis does not consider lowertier producers of standardised components or commodities, such as small electronic components or metal as such firms may exhibit different characteristics as they serve to multiple industries. Within the boundaries of our analysis, the effect seems quite robust. We also found that both size and the number of links decrease for firms in lower tiers, which might constrain their capacity to increase production when necessary, to handle multiple clients, or to diversify production (Fig. 4). Of course, we should be careful about the direction of causality-it might be that a smaller size is caused by the very fact that performance suffers, and/or the smaller these firms are, the more prone to performance fluctuations they can be. It is also worth noting that firms further away from the focal firm may be prone to information distortion but may be good at handling them to the extent that their performance is not affected.

The position of a supplier influences by how much it participates to the total flow of transactions in the supply chain. We examined the effects of this by counting each potential path that passes through a firm (supply network centrality). Our model hints 
at a diminishing returns effect between increased centrality and performance. While being central to the network gives the firm power and control (Kim et al. 2011), it also places much responsibility on its shoulders. Over centrality means an increased burden on internal resources to handle contracts and possibly excessive transaction costs. If the firm becomes increasingly dependent on external firms its performance may be likely to suffer from small disruptions on its dyad and beyond.

As we investigated the application of structural hole theory to supply networks, we found cautioning results. It became apparent not only that there is a difference between upstream and downstream structural patterns, but also that too many of them result in negative performance. In other words, too many closed, co-opetitive triads lead to negative performance. Both upstream and downstream triadic relationships result in financial performance increases for the firm, pointing out that both suppliers and buyers are financially better off when competing suppliers share links. This result confirms qualitative findings in sourcing-strategy literature, resulting in increased capacity through the pooling of resources, more business from the buyer due to efficiency increases, and the development of information and knowledge sharing culture (Wu and Choi 2005; Dubois and Fredriksson 2008). The second finding was that the buyers were slightly better off than suppliers in triadic relationships. However, the same observation might not hold for networks where there is not a strong client firm that has the power to make clients collaborate.

Structural holes resulted in diminishing productivity returns for both buyers and suppliers. The average firm within our sample financially benefitted from the downstream or upstream competition, however, its productivity was negatively affected by competition. This is an interesting dilemma where companies might have to choose between improving operational efficiency through increased embeddedness, which might help long-term growth prospects or improving financial returns through competition amongst buyers or suppliers.

While closed, coopetitive triads are financially good for buyers and suppliers, the results caution firms from engaging in both upstream and downstream triads, which results in diminishing returns. If a firm engages in a single upstream triad and a single downstream triad, the combined effect on the firm's performance will be $41 \%$ less on performance than if it engaged in a single buyer's triad, or $39 \%$ less than if it engaged in a suppliers triad. The increased complexity in relationships and operations may be two reasons behind this effect. First, suppliers find it hard to differentiate between competition and cooperation, and buyers may find it hard to mediate. Second, triads create loops in operational dependencies, possibly disturbing stability, because control is no longer linear. Third, triads mean more links and more transaction costs.

This study has certain limitations. The network we studied is a static snapshot, without transaction volume information. Transaction information could have allowed us to make more informed decisions as to what tier level is appropriate for the firm, and what production paths carry more weight, in turn allowing us also to sharpen our measures for supply network centrality. Similarly, longitudinal mapping of network structure and performance of firms would be valuable in differentiating between core and support networks, and understanding patterns of growth and shrinkage. 
We had to rely on firm revenues, productivity and other attributes ("Appendix A") as proxies for firm performance, as these were widely available, however, more fine-grained measures that quantify firm performance, may help further validate the findings of this study. Although the sample we employed is representative of the population of automotive manufacturers, there is a need to undertake a similar study for different industries to establish the generalisability of our findings. Similarly, there may be differences between Japanese and Western manufacturers' attitudes. Hence a further comparative study with Western automotive supply networks would be valuable.

Interesting questions arise for further research concerning performance and network structure. For example, are there sub-communities in the network that have more links with one another than the rest of the network? If so, what determines those clusters and do suppliers that lay between various communities of firms perform better than suppliers that only serve within communities? At the macroscopic level, an understanding of the whole network's performance and its relation to structure could be examined. Encouragingly, to an extent, our findings are corroborated by a recent study that highlights the potential of using network analysis to understand the link between supply chain embeddedness and financial performance of a focal company (Seiler et al. 2020). Our approach to metric design at the supply network level could be complimentary to network studies in industrial ecosystem level analyses and trade networks (e.g. Brintrup and Ledwoch 2018).

\section{Conclusions and managerial implications}

This study contributes to our understanding of performance effects of supply network embeddedness at the firm level. Prior research focused on small scale supply networks and extracted theoretical constructs regarding triadic sourcing strategies, while the other stream discussed how complex network theory could be applied to analyze supply chains. Our study contributes to the current research landscape in a multitude of ways: first, we investigated the performance effects of firm positioning within the network. Second, we devised a number of measures that help us analyze complex supply networks.

Our measures examined the effects of network centrality, supply network tier level, and the existence of upstream and downstream secondary relationships on firm performance.

Network embeddedness is a significant factor explaining performance in supply firms. The position that a firm embeds itself in the network determines the number of orders that it needs to handle and the amount of responsibility on its shoulders. The tier level it operates in determines its access to information. Its decision to form links with its indirect neighbours determines the competitive/cooperative culture surrounding it, which in turn affects the likelihood of success.

Triads give both buying and supplying firms performance returns that are higher than returns obtained by competition alone. However, pursuing both upstream and downstream co-opetition simultaneously seems to be suboptimal, possibly due to increased complexity and lower handling capacity. A similar lesson is found when considering the position of the firm in a supply network. Having many suppliers and clients increases the amount of responsibility that the firm has. And so does having suppliers with many 
suppliers themselves. While increased responsibility brings on increased performance, there is a threshold beyond which the effect diminishes and starts to impact firm performance negatively. We, therefore, suggest matching the appropriate level of centrality in the network with the level of the firm's capability to integrate internal competences and resources.

Of course, achieving all this requires knowledge of the network in which the firm finds itself. Today's supply networks are emergent, not designed. Hence companies need to be more attentive to their networks and gather data to form an understanding of their positioning. Data from independent intermediaries could be used as well as supporting new technologies such as supply chain mining (Wichmann et al. 2020) or supply chain link prediction (Brintrup et al. 2018). Modelling and simulation may help investigate the effect of structural change, relate network characteristics to performance potentially in wider industrial settings.

\begin{abstract}
Abbreviations
OEM: Original equipment manufacturer; SNC: Supply network centrality; SNTL: Supply network tier level; KS test: Kolmogorov-Smirnov test; LASSO: Least absolute shrinkage and selection operator; PERF: Performance; REV: Revenues; NP: Net profit; PROD: Labour productivity; EBITDA: Earnings before interest, tax, depreciation and amortization; TEV: Total enterprise value; BSH: Buyer's structural hole; BT: Buyer's triad; SSH: Supplier's structural hole; ST: Supplier's triad; AGE: Firm age; SIZE: Firm size; JAP: Japanese firm.
\end{abstract}

Acknowledgements

Not applicable.

Authors' contributions

AB devised network measures, collected and analysed data. SA performed regression analysis and interpreted results. Both authors wrote, read and approved the final manuscript.

Funding

The authors declare no specific funding sources for this work.

Availability of data and materials

The data that support the findings of this study are available from www.marklines.com and www.bloomberg.com but restrictions apply to the availability of these data, which were used under license for the current study, and so are not publicly available. Data are however may be available from the authors upon reasonable request and with permission of Marklines and Bloomberg.

Competing interests

The authors declare that they have no competing interests.

Author details

1 Said Business School, University of Oxford, Oxford OX1 1HP, UK. ${ }^{2}$ Department of Engineering, Institute for Manufacturing, University of Cambridge, Cambridge CB3 OFS, UK.

\title{
Appendix A: reliability, validity and robustness checks
}

In designing this study, we took several actions to ensure unbiased and objective calculation of the network metrics, and coding data on firm attributes such as size and performance. Two researchers were employed to program the calculation of network metrics and cross-validate firm attributes, who used two independent data sources and programming platforms. In addition the following robustness checks were carried out:

- We assessed the validity of revenues as a proxy of firm performance by explaining Net Income, EBITDA, and Total Enterprise Value (TEV) with our model on the subsample of firms for which this measure was available ( $46 \%$ of the firms). The results show agreement with the significance of network variables reported in our original model. 
- We included Mergers and Acquisitions as a control variable and reran the analysis with a binary variable which depicts whether the firm engaged in a merger or acquisition in the past 3 years. We found that Mergers and Acquisitions did not significantly influence performance of the sample firms.

- We validated the results of the GLS model by comparing it to the results obtained from a Lasso (Least Absolute Shrinkage and Selection Operator) regression. Lasso is shrinkage method that tackles multicollinaerity by selecting a subset of the most relevant variables for a given shrinkage parameter. By shrinking the redundant or less useful variables to zero, via the shrinkage parameter, Lasso offers enhanced interpretability of results. As stated by Tibrishani (1996), Lasso produces interpretable models like subset selection and has the stability of ridge regression. Specifically, given a dependent variable (output vector), denoted by say, $\mathbf{y}$, and a set of independent variables (input matrix), denoted by say, $\mathrm{X}$, the Lasso estimate can be defined as:

$$
\hat{\beta}_{\text {Lasso }}=\operatorname{argmin}_{\beta}\left\{\sum_{\mathrm{i}=1}^{\mathrm{N}}\left(y_{i}-\beta_{0}-\sum_{\mathrm{j}=1}^{\mathrm{P}} x_{i j} \beta_{j}\right)^{2}+\lambda \sum_{\mathrm{j}=1}^{\mathrm{p}}\left|\beta_{j}\right|\right\}
$$

where $\mathrm{N}$ denotes the length of the dependent variable, $\boldsymbol{\beta}_{\boldsymbol{j}}$ represents the coefficients estimated by minimizing the residual sum of squared (RSS) errors, P denotes the total number of input variables, $\boldsymbol{x}_{\boldsymbol{i}}$ denotes ith row and jth column of the independent variable matrix $\mathrm{X}$, while $\lambda$ denotes the shrinkage parameter that penalizes inclusion of variables in the model. In the context of this work, $X$ represents the different inter-correlated variables outlined in Table 5, while y represents performance. In this study, we obtained Lasso estimate for a range of different values of the shrinkage parameter $\lambda$ starting from zero, to a maximum value that allows the coefficients of all explanatory variables to be reduced to zero. Note that for $\lambda$ equal to zero, Lasso is the same as least squares regression, whereby all variables are included in the model. However, as we increase $\lambda$, coefficients of less informative/redundant variables are shrunk to zero, thus allowing us to obtain a relative ranking of the different variables for the given dataset. We found that the conclusions based on the results obtained using Lasso were similar to the ones obtained using GLS regression.

\section{Appendix B: factor analysis}

We employ explanatory Factor Analysis (FA), see (Tabachnick and Fidell 2001), to summarize the relationship between different inter-correlated variables used in this study. Similar analysis has been employed by Tucker (2004) for analyzing the impact of different variables on operational failure in healthcare. FA is a statistical technique commonly used for dimension reduction. Basically, FA allows the extraction of a small set of uncorrelated variables from a large set of correlated variables. As stated in Tabachnick and Fidell, variables that are correlated with one another, but independent of other variables, are combined into factors. The correlation between each variable and a given factor is termed as 'factor loading' of the variable on the factor, whereby a larger loading means that the variable is more relevant for that factor. In this study, we extract three factors, which capture the highest proportion of variance in the data. We applied VARIMAX 
Table 7 Factor analysis

\begin{tabular}{lccc}
\hline & Factor $\mathbf{1}$ & Factor $\mathbf{2}$ & Factor 3 \\
\hline 1. SIZE & 0.35 & 0.122 & -0.042 \\
2. SNTL1 & -0.11 & -0.259 & 0.246 \\
3. PUB & 0.033 & $\mathbf{0 . 5 3 8}$ & 0.069 \\
4. JAP & 0.049 & $\mathbf{0 . 7 5 7}$ & 0.089 \\
5. AGE & -0.047 & $\mathbf{0 . 4 8 1}$ & -0.130 \\
6. SNC & $\mathbf{0 . 9 8 2}$ & -0.023 & 0.155 \\
7. BSH & $\mathbf{0 . 9 8 9}$ & -0.011 & 0.041 \\
8. BT & $\mathbf{0 . 9 5 9}$ & -0.003 & 0.067 \\
9. SSH & 0.348 & 0.090 & $\mathbf{0 . 5 6 2}$ \\
10. SST & $\mathbf{0 . 9 4 8}$ & -0.009 & 0.310 \\
\% Variance & 40.21 & 11.85 & 5.34 \\
\hline
\end{tabular}

Significant variables with loading greater than 0.45 are depicted in bold

rotation, as also used in Tucker (2004), in order to obtain orthogonal components. The first three factors, presented in Table 7 , cumulatively explain approximately $57 \%$ of the variance. Following Tucker (2004) and (Tabachnick and Fidell 2001), variables with loading greater than 0.45 were considered to be useful for analysis.

Table 7 shows our results.

If we go by Tucker (2004), then only numbers in the above table (factor loading) greater than 0.45 are useful. This means that for Factor 1, SNC, BSH, BT and SST group together (complexity), and are most important. For Factor 2, we have PUB, JAP, AGE. For Factor 3, we have SSH. If we wanted to include more variables for a given factor, we could lower the threshold from 0.45 , to say, 0.30 .

Factor 1, which captures the highest variance, is termed as complexity, and explains $40.21 \%$ of the total variation in the data set. The variables that had maximal loading on this component were those variables that investigated complex network effects on performance: Supply Network Centrality, Suppliers' and Buyers' Triads, and Buyers' Structural holes.Thus this analysis shows first that complex network variables can explain performance to a significant degree, and that the network effect can be bundled into one factor that represents the way in which a firm is embedded in its extended network.

The second factor we extracted includes non-network related control variables, and explained $11.85 \%$ of the variance. The variables that maximally loaded on the second component were: firm size, age, whether a firm was public and whether a firm was Japanese.

Finally, the third factor, competition, explains $5.34 \%$ of the variance. This factor addresses the extent to which a firm competed with other suppliers serving to the same customers (SSH).Thus representing competition with suppliers that have overlapping product portfolios with the firm and could be substituted. 
Table 8 Example product categories

\begin{tabular}{|c|c|c|c|c|c|c|c|}
\hline Level 0 & & Level 1 & & Level 2 & & Level 3 & \\
\hline \multirow[t]{10}{*}{15} & Engine & 1515 & $\begin{array}{l}\text { Gas fuel } \\
\text { injection } \\
\text { system }\end{array}$ & 151502 & Fuel rail & & \\
\hline & & & & 151504 & Fuel injector & 15150402 & Fuel injection nozzle \\
\hline & & & & & & 15150404 & $\begin{array}{l}\text { Fuel injection nozzle } \\
\text { holder }\end{array}$ \\
\hline & & & & 151506 & $\begin{array}{l}\text { Electronic throttle } \\
\text { control system }\end{array}$ & & \\
\hline & & & & 151508 & Throttle body & 15150802 & Throttle valve \\
\hline & & & & 151510 & Air flow meter & & \\
\hline & & & & 151512 & Pressure regulator & & \\
\hline & & & & 151514 & $\begin{array}{l}\text { Idle rotation control } \\
\text { valve }\end{array}$ & & \\
\hline & & & & 151516 & Swirl control valve & & \\
\hline & & & & & Fuel rail & & \\
\hline
\end{tabular}

Table 9 Example firm product offering

\begin{tabular}{ll}
\hline Firm 895 & \\
\hline 15150402 & Fuel injection nozzle \\
152002 & Diesel fuel injection pump \\
601008 & Shaft \\
\hline
\end{tabular}

\section{Appendix C: sample product data}

Data consists of 819 main product categories offered by firms. An example categorisation is shown on Table 8. Level 0 is the main part category. Each level is divided into further sub-categories that are needed to produce the part at the higher-level. Firms declare their production capability at levels 1,2 or 3 as shown on Table 9. We assume that a firm which declares that it makes a fuel injection nozzle does not necessarily produce the whole gas fuel injection system, and therefore do not generalise to higher level categories. For example Firm 895 produces the fuel injection nozzle, but does not produce other components making the gas fuel injection system. Another component Firm895 makes is a diesel fuel injection pump, defined under the diesel fuel injection system category.

Received: 8 April 2020 Accepted: 8 February 2021

Published online: 25 February 2021

\section{References}

Asanuma B (1994) Manufacturer-supplier relationships in Japan and the concept of relation-specific skill. J Jpn Int Econ 3:1-30

Barrot JN, Sauvagnat J (2016) Input specificity and the propagation of idiosyncratic shocks in production networks. Q J Econ 131:1543-1592

Bernard AB, Moxnes A, Saito YU (2014) Geography and firm performance in the Japanese production network (No. 14-E034), RIETI discussion paper series. Research Institute of Economy, Trade and Industry, Tokyo

Blondel VD, Guillaume J-L, Lambiotte R, Lefebvre E (2008) Fast unfolding of communities in large networks. J Stat Mech Theory Exp 2008(10):1-12

Borgatti S, Li X (2009a) On social network analysis in a supply chain context. J Supply Chain Manag 45(2):5-22 
Borgatti SP, Li X (2009b) (2009) On social network analysis in a supply chain context. J Supply Chain Manag 45(2):5-22 Bozarth CC, Warsing DP, Flynn BB, Flynn EJ (2009) The impact of supply chain complexity on manufacturing plant performance. J Oper Manag 27:78-93

Brintrup A (2011) Mapping the Toyota network: the emergence of resilience. Said Business School working paper 2011-05-012

Brintrup A, Ledwoch A (2018) Supply network science: emergence of a new perspective on a classical field. Chaos Interdiscip J Nonlinear Sci 28(3):033120

Brintrup A, Kito T, New S, Reed-Tsochas F (2011) From transaction cost economics to food webs: a multi-disciplinary discussion on the length of supply chains. EUROMA, Cambridge

Brintrup A, Wichmann P, Woodall P, McFarlane D, Krechel W, Nicks E (2018) Predicting hidden links in supply networks. Complexity. https://doi.org/10.1155/2018/9104387

Burt R (1992) Structural holes: the social structural of competition. Harvard University Press, Cambridge, MA

Carnovale S, Yeniyurt S (2015) The role of ego network structure in facilitating ego network innovations. Journal of Supply Chain Management 51(2):22-46

Chen IJ, Paulraj A (2004) Towards a theory of supply chain management: the constructs and measurements. J Oper Manag 22:119-150

Cingolani I, Panzarasa P, Tajoli L (2017) Countries' positions in the international global value networks: centrality and economic performance. Appl Netw Sci 2:21

Cohen P, Cohen J, West SG, Aiken LS (2003) Applied multiple regression/correlation analysis for the behavioural sciences, 3rd edn. Erlbaum, Hillsdale, NJ

DiMaggio PJ, Powell WW (1983) The Iron Cage Revisited: Institutional isomorphism and collectivity rationality in organizational fields. Am Sociol Rev 48(2):147-160

Dubois A, Fredriksson P (2008) Cooperating and competing in supply networks: making sense of a triadic sourcing strategy. Journal of Purchasing and Supply Management 14:170-179

Dyer JH, Nobeoka K (2000) Creating and managing a high-performance knowledge-sharing network: the Toyota case. Strateg Manag J 21(3):345-367

Echols A, Tsai W (2005) Niche and performance: the moderating role of network embeddedness. Strateg Manag J 26(3):219-238

Evan WM (1966) The organization-set: toward a theory of inter-organizational relations. In: Thompson JD (ed) Approaches to organizational design. University of Pittsburgh Press, Pittsburgh, pp 174-190

Fujiwara Y, Aoyama H (2010) Large-scale structure of a nation-wide production network. Eur Phys J B 77:565-580

Gargiulo M, Benassi M (2000) Trapped in your own net? Network cohesion, structural holes, and the adaptation of social capital. Organ Sci 11(2):183-196

Granovetter MS (1985) Economic action and social structure: the problem of embeddedness. Am J Sociol 91 (3):481-510

Greene WH (2012) Econometric analysis, 7th edn. Prentice Hall, Upper Saddle River, NJ

Greve HR, Baum JAC, Mitsuhashi H, Rowley T (2010) Built to last but falling apart: cohesion, friction and withdrawal from interfirm alliances. Acad Manag J 53(2):302-322

Inoue H, Todo Y (2019) Firm-level propagation of shocks through supply-chain networks. Nat Sustain 2:841-847

Jaccard J, Wan CK, Turrisi R (1990) The detection and interpretation of interaction effects between continuous variables in multiple regression. Multivar Behav Res 25:467-478

Kashiwagi Y, Matous P, Todo Y (2018) International propagation of economic shocks through global supply chains (No. E1810), WINPEC working paper. Waseda Institute of Political Economy, Waseda University, Tokyo

Kennedy P (1996) A guide to econometrics, 3rd edn. MIT Press, Cambridge, MA

Kim Y, Choi TY, Yan T, Dooley K (2011) Investigation of supply networks: a social network analysis approach. J Oper Manag 29(3):194-211

Krackhardt D (1998) Super strong and sticky. In: Kramer RM, Neale MA (eds) Power and influence in organizations. Sage, Thousand Oaks, p 21

Lawson B, Tyler BB, Cousins PD (2008) Antecedents and consequences of social capital on buyer performance improvement. J Oper Manag 26:446-460

Lee HL, Padmanabhan V, Whang S (1997) Information distortion in a supply chain: the bullwhip effect, management science. Front Res Manuf Logist 43(4):546-558

Lincoln JR, Shimotani M (2009) Whither the keiretsu, Japan's business networks? How were they structured? What did they do? Why are they gone?, Working paper series, Institute for Research on Labor and Employment, UC Berkeley

Lomi A, Pattison P (2006) Manufacturing relations: an empirical study of the organization of production across multiple networks. Organ Sci 17(3):313-332

Mizuno T, Souma W, Watanabe T (2014) The structure and evolution of buyer-supplier networks. PLoS ONE 9:e100712

Morgan RM, Hunt SD (1994) The commitment-trust theory of relationship marketing. J Mark 58(3):20-38

Nakamoto T, Chakraborty A, Ikeda Y (2019) Identification of key companies for international profit shifting in the Global Ownership Network. Appl Netw Sci 4:58

Nishiguchi T (1994) Strategic industrial sourcing: the Japanese advantage. Oxford University Press, New York

Nishiguchi T, Beaudet A (1998) The Toyota Group and Aisin Fire. Sloan Manag Rev 40(1):49-59

Ohnishi T, Takayasu H, Takayasu M (2009) Hubs and authorities on Japanese inter-firm network: characterization of nodes in very large directed networks. Prog Theor Phys Suppl 179:157-166

Ohnishi T, Takayasu H, Takayasu M (2010) Network motifs in an inter-firm network. J Econ Interact Coord 5:171-180

Okamuro H (2001) Risk sharing in the supplier relationship: new evidence from the Japanese automotive industry. J Econ Behav Organ 45(4):361-381

Pfeffer J, Salancik GT (1978) The external control of organizations: a resource dependence perspective. Stanford University Press, Stanford

Phillips J, Liu B, Costello T (1998) A balance theory perspective of triadic supply chain relationships. J Mark Theory Pract Spec Issue 1998:78-91

Podolny JM (1993) A status-based model of market competition. Am J Sociol 98(4):829-872 
Powell WW (1990) Neither market nor hierarchy: network forms of organization. Res Organ Behav 12:295-336

Powell WW, White DR, Koput KW, Owen-Smith J (2005) Network dynamics and field evolution: the growth of interorganizational collaboration in the life sciences. Am J Sociol 110(4):1132-1205

Rothaermel FT (2001) Incumbent's advantage through exploiting complementary assets via interfirm cooperation. Strateg Manag J Spec Issue 22(6-7):687-699

Saito YU, Watanabe T, Iwamura M (2007) Do larger firms have more interfirm relationships? Phys A Stat Mech Its Appl 383:158-163 (Econophysics Colloquium 2006 and Third Bonzenfreies Colloquium)

Sambharya RB, Banerji K (2006) The effect of keiretsu affiliation and resource dependencies on supplier firm performance in the Japanese automobile industry. Manag Int Rev 46(1):7-37

Schmenner RW, Swink ML (1998) On theory in operations management. J Oper Manag 17(1):97-113

Seiler A, Papanagnou C, Scarf P (2020) On the relationship between financial performance and position of businesses in supply chain networks. Int J Prod Econ 227:107690

Sørensen JB, Stuart TE (2000) Aging, obsolescence, and organizational innovation. Adm Sci Q 45:81-112

Sturgeon TJ (2002) Modular production networks: a new American model of industrial organization. Ind Corp Change 11(3):451-496

Tabachnick BG, Fidell LS (2001) Using multivariate statistics, 4th edn. Allyn \& Bacon, Boston, MA

Tibrishani R (1996) Regression shrinkage and selection via the lasso. J R Stat Soc Ser B 58(1):267-288

Todo Y, Nakajima K, Matous P (2013) How do supply chain networks affect the resilience of firms to natural disasters? evidence from the great East Japan earthquake (No. 13-E-028), discussion paper series. RIETI

Tucker AL (2004) A case study of operational failure in home healthcare. J Healthc Qual 26(3):38-43

Uzzi B (1997) Social structure and competition in interfirm networks: the paradox of embeddedness. Adm Sci Q 42(1):35-67

Uzzi B, Gillespie JJ (2002) Knowledge spillover in corporate financing networks: embeddedness and the firm's debt performance. Strateg Manag J 23:595-618

Van Ackere A, Larsen AR, Morecroft JDW (1993) Systems thinking and business process redesign: an application to the beer game. Eur Manag J 11(4):412-423

Wagner SM, Bode C (2006) An empirical investigation into supply chain vulnerability. J Purch Supply Manag 12(6):301-312

Wichmann P, Brintrup A, Baker S, Woodall P, McFarlane D (2020) Extracting supply chain maps from news articles using deep neural networks. Int J Prod Res 58(17):5320-5336

Wilhelm MM, Kohlbacher F (2011) Co-opetition and knowledge co-creation in Japanese supplier-networks: the case of Toyota. Asian Bus Manag 10(1):66-86

Wu Z, Choi TY (2005) Supplier-supplier relationships in the buyer-supplier triad: building theories from eight case studies. J Oper Manag 24:27-52

Yan T, Choi TY, Kim Y, Yang Y (2015) A theory of the nexus supplier: a critical supplier from a network perspective. J Supply Chain Manag 51(1):52-66

\section{Publisher's Note}

Springer Nature remains neutral with regard to jurisdictional claims in published maps and institutional affiliations.

\section{Submit your manuscript to a SpringerOpen ${ }^{\circ}$ journal and benefit from:}

- Convenient online submission

- Rigorous peer review

- Open access: articles freely available online

- High visibility within the field

- Retaining the copyright to your article

Submit your next manuscript at $\gg$ springeropen.com 